\title{
EARLY COST SAFETY ANALYSIS OF RUNWAY EVENTS
}

\author{
Rob van Eekeren ${ }^{1}$, Stephen Wright ${ }^{2}$, Olja Čokorilo ${ }^{3}$ \\ ${ }^{1}$ Safe-runway GmbH, Route de Nendaz, Nendaz, VS, Switzerland \\ ${ }^{2}$ Faculty of Engineering, University of Leeds, Leeds LS2 9JT, UK \\ ${ }^{3}$ University of Belgrade, Faculty of Transport and Traffic Engineering, Vojvode Stepe 305, 11000 Belgrade, Serbia
}

Received 20 April 2018; accepted 10 June 2018

\begin{abstract}
The importance to airport safety related events has grown significantly in recent years. Runway safety events continue to pose a real and genuine challenge to the aviation community. This article addresses how could an acceptable risk for accidents or runways be achieved. It considers what would be an objective method to establish if and which mitigations are necessary. Global estimations show that runway related accidents and incidents, cost the aviation industry an average of $\$ 500$ Million per month. Therefore, a cost-benefit system analysis has the potential to greatly reduce these worldwide costs. It is also an excellent indicator for which subjects, areas and operators to address. The results highlight that present runway safety priorities need to be altered in order to stay / become effective. Obtained conclusions would be a great platform for new risk mitigation and / or reduction safety measures development regarding runway events.
\end{abstract}

Keywords: aviation, runway, safety, costs, accidents.

\section{Introduction}

The majority of aviation accidents occur on or near runways. These results in damage to equipment or property, extra operational costs, additional costs, loss of turnover (opportunity costs) and endanger human lives. The expected growth of aviation requires improved runway safety levels in order to keep the accident numbers at least at the same level. Therefore, two types of measures are provided within civil aviation authorities worldwide: regulation and financial safety measures. Regulation measures include SSP (State Safety Program) development and implementation. Within the provided regulatory framework, the law of diminishing return however might pose future financially motivated restrictions. Therefore cost effective runway risk mitigations are necessary. This paper deals with the accident cost estimation, which could provide a good platform for cost-benefit assessment particularly when authority or companies plan to improve existing safety level within the regulatory framework. Risk is a function of likelihood and severity. A method in quantifying the risks associated with runway accident / incidents risk is to express it in costs. That implies that a indication of the level of risk could be the associated costs.

In order to establish if a further increase in safety is grossly outweighed by the costs at which the As Low As Reasonably Practicable (ALARP) (ICAO, 2009) level of safety is reached, (EASA, 2015) defines ALARP as "Showing that the safety risk is ALARP means that any further risk reduction is either impracticable or grossly outweighed by the cost". Thus insight in the specific costs of runway safety costs

${ }^{1}$ Corresponding author: robvaneekeren@safe-runway.com 
and their mitigations is needed to establish priorities in mitigations or acceptance as the associated risks as they are. According to (Eekeren et al., 2017) a method in classifying and estimating the runway accident / incident costs is divided into four categories: aerodrome operator costs, aircraft operator costs, indirect safety costs and the human injury and fatality costs.

\section{Literature Review}

A cost safety analysis requires a detailed evaluation from different perspectives of the subjects involved. Nowadays, different methods and tools are used in aviation safety risks analysis: statistical analysis, trend analysis, normative comparisons, simulation and testing, expert panel, costbenefit analysis (Čokorilo and Dell'Acqua, 2013; Čokorilo et al., 2014; Ericson, 2016). Other authors (Moretti et al., 2018) address a methodology to assess the probability of a veer-off accident at any airport, based on statistical data collected throughout the world on previous events. It defines a method which can be implemented in order to manage risks, by taking into account the runway devices which are available during the operations.

Generally, cost benefit assessment provides an excellent platform for safety improvements and mitigation measures. Due to the nature of aviation accidents, those cost evaluations could vary from case to case and therefore it is hard to establish unique evaluation for all provided accidents (Čokorilo et al.,2010; Čokorilo, 2008; Eekeren et al., 2017). This paper provides accident cost analysis based on runway safety events.

\section{Data Collection and Results}

Over the past three years (1 January 2015 until 1 May 2018; "the period") are the total costs related to runway accidents and incidents estimated. These compromise all types of motorized fixed wing aircraft, at all types of aerodromes, airports and strips and all types of operations, including military and government. The database contains 2100 runway related accidents and (severe) incidents. The costs of these are corrected for local purchasing power. All publically know events are accounted for, but a certain percentage of non-reporting especially at some countries and regions as well as some misreporting cannot be excluded. Therefore the below presented figures are rather conservative (the actual figures might be higher).

\section{Runway Accidents / Incident Costs}

In the observed period, following cost distribution is recorded: $68 \%$ of the worldwide runway accidents / incident costs related to aircraft operators, $5 \%$ to human injuries and fatalities, $25 \%$ to indirect safety costs and only $2 \%$ to aerodrome operators (Fig.1). For example, the costs for aircraft operators are not only restricted to damage, but also include extra operational costs, diversions, delays, passenger compensations, etc. (Čavka and Čokorilo, 2012) describe a method of calculating the Indirect Safety Costs (ISC). These ISC include a vast number of indirect costs such as insurance premiums, search and rescue, wreckage removal, accident investigation, etc. Ultimately passenger and tax payers will pay, which really put authorities in the driving seat of enabling reduction of avoidable costs. 


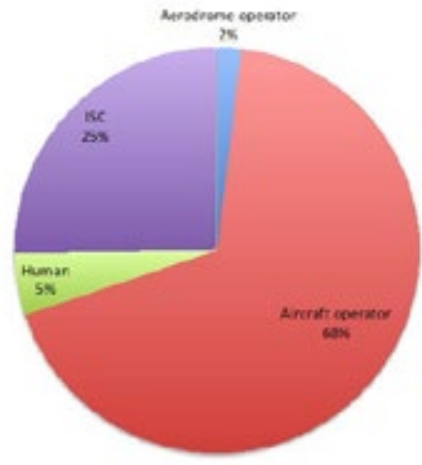

Fig. 1.

Runway Costs Distribution Entities

Source: (Safe-Runway, 2018)

This large financial difference between who pays, prevents an aviation industry costs effective approach. E.g. why should an aerodrome operator invest in runway safety system (ICAO standard, recommended RESA, runway strip, design out incursions, etc.) while only $2 \%$ would be saved for them, whilst an aircraft operator would bear almost $70 \%$ of the costs? The silo structure in civil commercial aviation blocks a cost effective approach and thus leaves cost effective safety improvements unused.

\subsection{Total Cumulative Costs}

The total costs of runway accidents or incidents during the period are estimated at \$20 Billion US dollar (corrected for local purchasing power). That relates to an average of $\$ 500$ Million per month (Fig. 2.). Monthly variations are distinctive (mind 2018 Q1 is in also incorporated). There is no clear indication of runway significant reduction of runway accidents costs over the period (Fig. 3.).

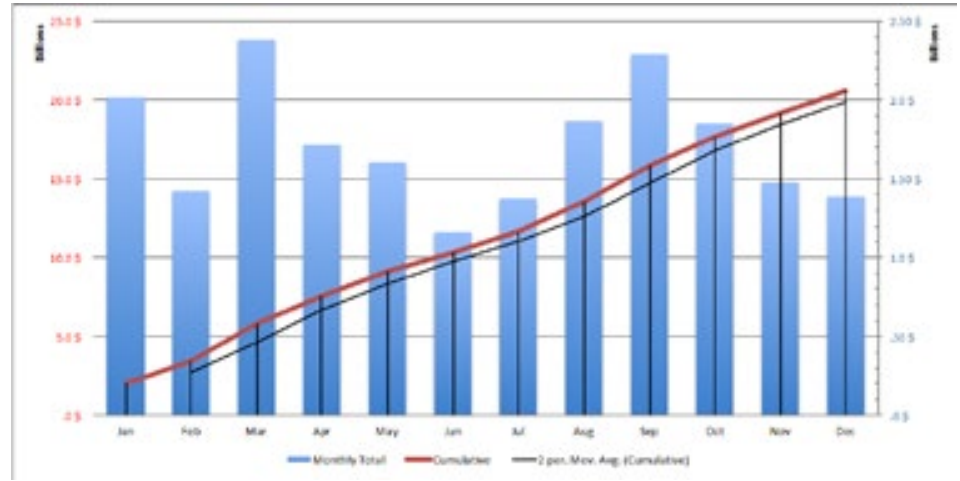

Fig. 2.

Runway Total Accident Costs from 2015 to 2018

Source: (Safe-Runway, 2018) 


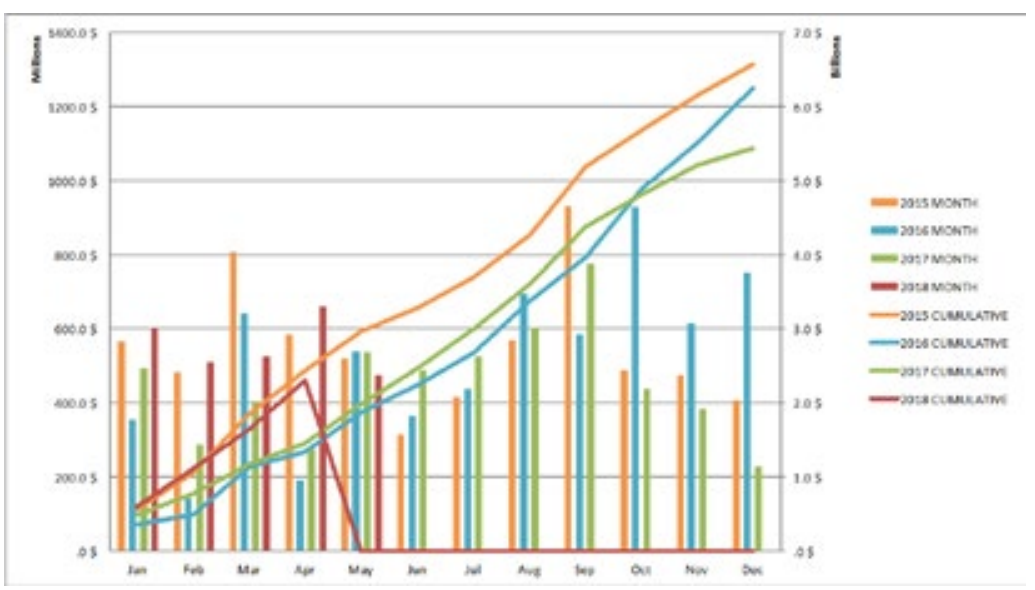

Fig. 3.

Monthly Cost of Runway Events from 2015 to 2018

Source: (Safe-Runway, 2018)

\subsection{Type of Operation}

The largest costs are associated with Commercial Air Traffic (59\%) (Fig. 4.). General aviation and military runway accidents costs are each around $15 \%$ (Fig.3.). General aviation has the highest number of casualties and injuries (GEN
\#600 and almost \$ 500 Million); for Commercial Air Transport are these (CAT \#350 and almost \$300 Million). GEN has also by far the highest number of runway events (GEN >1250; CAT 430). The average costs per runway event are for CAT over ten times than for GEN ( $\$ 26.8$ Million per event 2.2 Million).

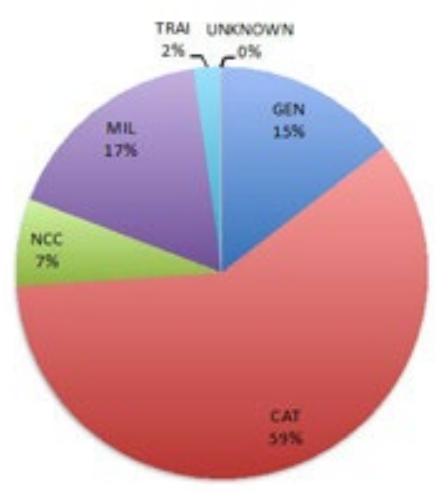

Fig. 4.

Total Cost Distribution per Type of Operation from 2015 to 2018

Source: (Safe-Runway, 2018) 


\subsection{Type of Aerodrome}

The highest costs occur at regional aerodromes ( $42 \%)$, followed by Hub's (32\%), Municipal (15\%) and finally at military airports (11\%) (Figure5). (Boeing, 2017) expects strong growth in point-to-point and
LLC traffic. It might therefore be logical to conclude that future growth will include largely regional aerodromes.

Without proper mitigations a further high increase of the runway event costs at regional aerodromes could be expected.

\section{Fig. 5.}

Runway Accident Costs per Aerodrome Type from 2015 to 2018

Source: (Safe-Runway, 2018)

\subsection{Type of Runway Event}

Developed database records events which are classified in runway incursions, runway excursions (consisting of underruns, veer-offs and overruns) and "on runway events". An "on runway event" is when runway operations are hampered due to an occurrence (e.g. EK521 at Dubai
3 Aug2016; refer to (GCAA, 2016) and also include emergency landings and e.g. evacuations. Runway excursions contribute for $60 \%$ ( $\$ 11.8$ Billion) of the costs (Fig. 6), on runway events $37 \%$ (\$ 7.3 Billion) and runway incursions for $1 \%$ (\$177 Million). The costs associated with runway veer offs are estimated at almost $\$ 7$ Billion. 


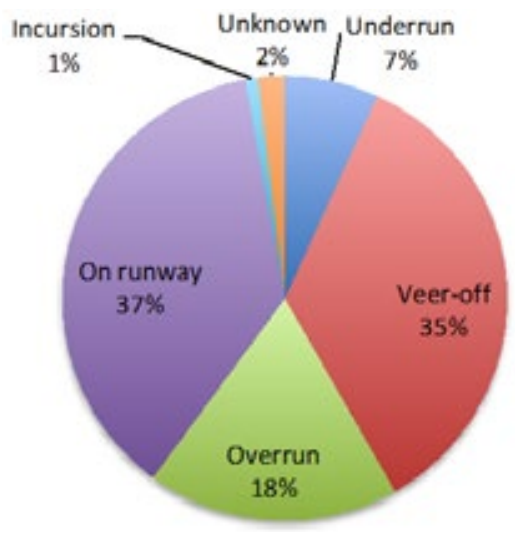

Fig. 6.

Runway Accident Costs per Type Event from 2015 to 2018

Source: (Safe-Runway, 2018)

The costs distribution provides a clear insight in the problem areas. The top issues are: number of casualties in General aviation; the high cost per event for CAT; the large imbalance on who pays; runway excursions with emphasis on veer-offs and regional aerodromes (Fig. 7).

\subsection{Regions}

At present time (Spring 2018) there are 112 countries in the developed Safe-Runway Gmbh database. The USA has a matured reporting system and has the most runway events. The highest costs however occur in Asia (Fig. 8). The EASA region is second in the number of events and third for the costs. It proved very difficult to find Chinese runway safety events via open sources, thus an underreporting might be likely for the Asian region.
Since the risk is expressed in terms of predicted probability and severity, of the consequence(s) of a runway events, this paper seeks to discover whether aviation safety measures are cost-effective by considering their effectiveness based on total costs of potential runway event.

It could be seen from Fig. 8 that the costs are the highest in the Middle East, followed by Asia and Non EASA Europe, and USA.

The influence to aviation safety by the FAA, with spin offs also outside the USA, justifies the efforts and investments of the FAA on reducing the risks and costs associated with runway occurrences. This however should not preclude that other region where the costs are higher should not invest (much) more. 


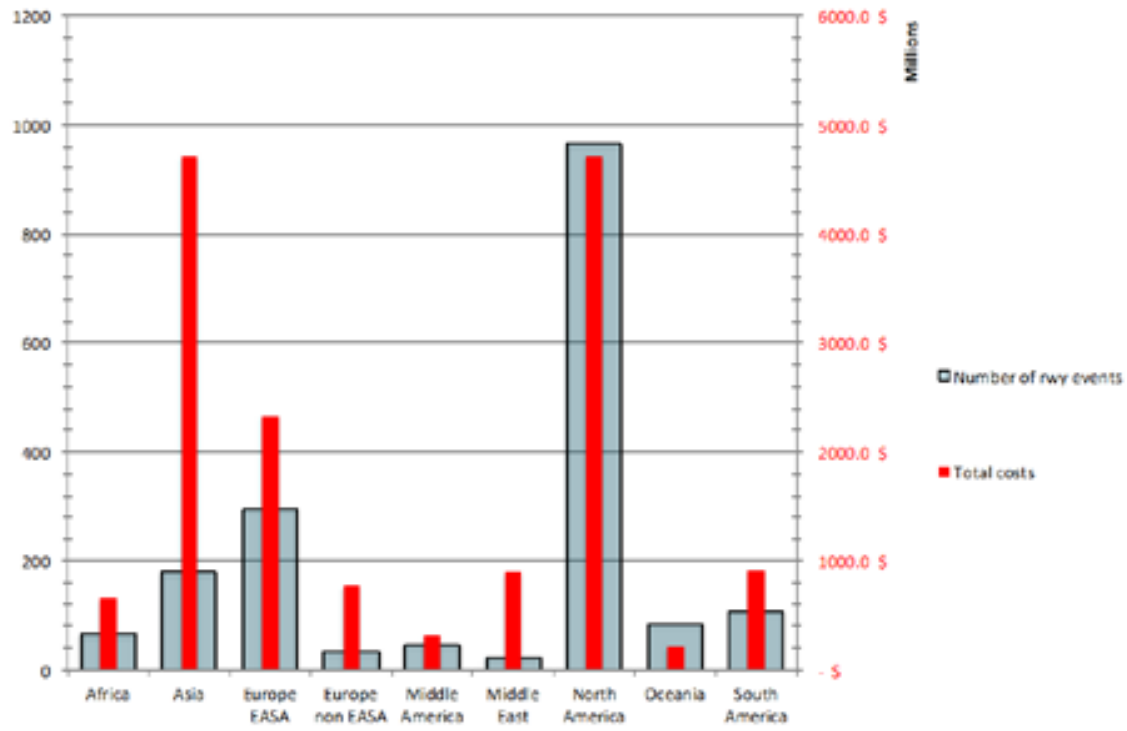

Fig. 7.

Number and Costs per Region from 2015 to 2018

Source: (Safe-Runway, 2018)

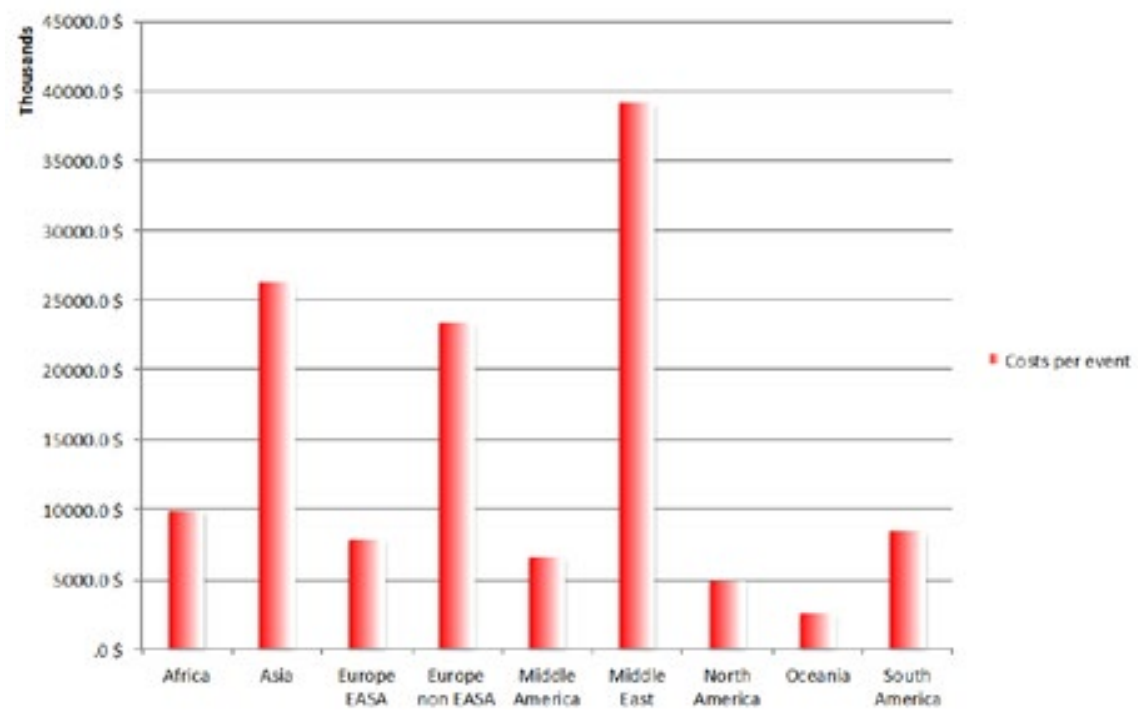

Fig. 8.

Average Cost per Region from 2015 to 2018

Source: (Safe-Runway, 2018) 


\section{Discussion and Conclusions}

According to provided data analysis several questions are occurred: why is it extremely unlikely that a flight commences with a nonlicensed crew or with an aircraft not meeting ICAO certification standards, whilst at the same time accidents occur at airports that not meet minimum requirements? For example, the Pegasus 8622 occurrence on $13^{\text {th }}$ January 2018, saw a B737 runway veering off at Trabzon (Fig. 9), that illustrates a runway strip of $30 \%$ of the (ICAO, 2016) standard at the accident location. What would have been the safety / risk analysis of accepting operations to these type of non-compliant airports?

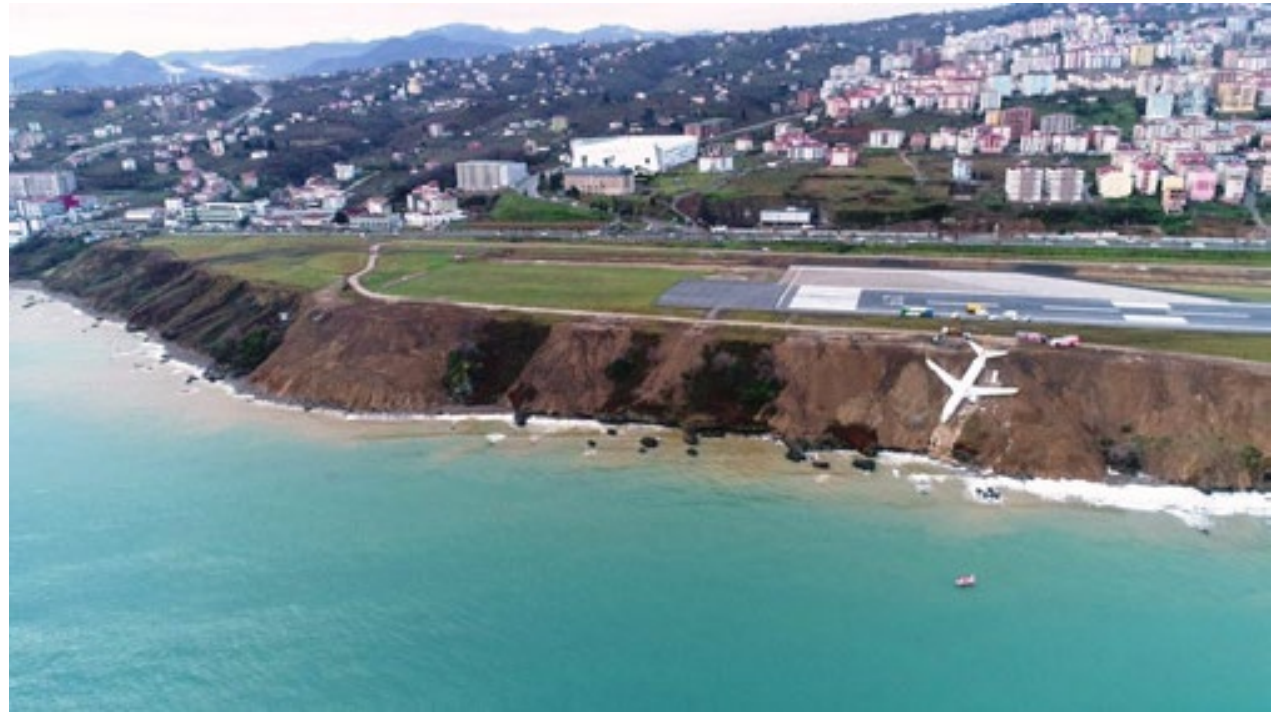

Fig. 9.

Pegasus 8622 Flight Veer-off at Trabzon

Source: (ASN, 2018)

The ICAO wording "wherever practicable" seems not always being used in the true meaning of the intention. For example, it is not defendable that an airport has far to soft ground in the runway strip causing damage rather than preventing it. But then again, why would an airport invest if the aircraft operator bears the costs?

This large cost differentiation on "who pays" restricts a joined industry cost effective risk approach. A cost-benefit approach would however open new mitigations, increase safety whilst at the same time reduce the overall costs. Despite of all efforts to reduce the likelihood of a runway safety event, reality shows that these occur nevertheless. Thus investing in severity reducing systems might prove cost beneficiary. The goal of a "follow the money policy" should be to find cost effective specific mitigations for enhancing runway safety and, at the same time, reduce the overall costs related to these events. E.g. one should ask what would be more cost effective: Bring the runway strip at certain airports to standard or even beyond, 
or extra operational restrictions, or stringent training programs, or on board equipment throughout the fleet, etc.

Runway excursion risk reduction: (ICAO, 2007) and (Eurocontrol, 2017) show emphasis on preventing runway incursions, which has proven to be successful and have resulted in just a fraction of the costs of related to runway excursions and especially veer offs. The national runway safety plan (FAA, 2014) includes next to incursions also to a certain extend excursions. It is very unlikely that the runway excursion risk will vanish by itself. An aimed worldwide and European program is required.

General aviation: Data show that most underruns occur with light aircraft after losing engine power followed by trying to return to land. Another factor is the gear failures. Authorities should ask if the high number of injuries and fatalities in general aviation are acceptable. Possible solutions should address: reduction of engine failures, improving engine / fuel reliance; pilot training and new infrastructure for emergency landings.

Commercial Air Traffic: The majority of the veer off costs relate to broken gears, including running into too soft ground in the (none designed standard (ICAO, 2006)) runway strip. Cross winds, slippery runways and (heavy) rain are often related to the accident. Climate change scenarios indicate the likelihood of increased short severe weather outbursts; thus heavy rain accompanied with more (cross-) wind. Possible solutions relate to improved runway strips, more stringent crosswind limitations, better forecasts (also on the very, very short term), aircraft predictive veeroff systems, increased runway drainage, runway friction, etc. Preventing overruns as well as reducing the effects of runway overruns are next to pilot training at the moment also addressed via the various technical systems, These include, but are not limited to aircraft overrun preventing systems, improved braking systems, engineered material arresting systems. (FAA, 2005) estimates EMAS at \$3.8 Million per bed and lists (FAA, 2018) 12 actual arrestments. Safe-Runway $\mathrm{GmbH}$ calculated the net costs saved at \$ 1 Billion.

\section{Summary of Conclusions and Recommendations}

Risk can be expressed in costs. The most runway safety gain can be achieved in the Middle East, Asia and Non-EASA Europe. An improved effort to reduce the risks associated with veer-offs is needed as is reduction of the runway occurrences at regional aerodromes. The high number of injuries and fatalities in general aviation needs to be reduced. For CAT operations is a joined aviation industry cost effective approach needed. A mutual runway safety fund could be a potential first step to enable a cost effective reduction of the runway safety risk. That can only be achieved when aircraft operators, aerodrome operators, manufacturers and authorities join up and find a solution for the current financial silo structure for CAT operations. This requires strong leadership and guidance by an independent organization (for Europe e.g. the European Commission).

\section{References}

ASN. 2018. Aviation Safety Network Database. Available from internet: <https://aviation-safety.net/database/ record.php?id=20180113-0>. Accessed on: 23-04-18. 
Boeing. 2017. Current Market Outlook 2017-2026. Boeing, Seattle, USA. 64 p.

Čavka, I.; Čokorilo, O. 2012. Cost-benefit assessment of aircraft safety, International Journal for Traffic and Transport Engineering 2(4): 359-371.

Čokorilo, O. 2008. Risk Management Implementation In Aircraft Accident Cost Analysis. In Proceedings of the 12nd Annual World Conference, Air Transport Research Society (ATRS) World Conference, July 6-10, Athens, Greece.

Čokorilo, O.; Gvozdenovic, S.; Vasov, Lj.; Mirosavljevic, P. 2010. Costs of unsafety in aviation, Technological and economic development of economy 16(2): 188-201. doi: 10.3846/tede.2010.12.

Čokorilo, O.; Dell'Acqua, G. 2013. Aviation Hazards Identification Using Safety Management System (SMS) Techniques. In Proceedings of the 16th International conference on transport science ICTS 2013, 2013 27th May; Portorož, Slovenia, 66-73.

Čokorilo, O.; De Luca, M.; Dell’Acqua, G. 2014. Aircraft safety analysis using clustering algorithms, Journal of Risk Research 17(10): 1325-1340.

EASA. 2015. NPA 2015-18(b) - Update of the rules on air operations. European Aviation Safety Agency, Cologne, Germany. 117 p.

Ericson, C.A. 2016. Hazard Analysis Techniques for System Safety. Second edition, Wiley, Fredericksburg, Virginia. $616 \mathrm{p}$.

EUROCONTROL. 2017. European Manual on the Prevention of Runway Incursions. $156 \mathrm{p}$.

FAA. 2004. Financial Feasibility and Equivalency of Runway Safety Area Improvements and Engineered Material Arresting Systems--Order 5200.9. Federal Aviation Administration, Washington. USA.
FAA. 2014. National runway safety plan 2015-2017. Federal Aviation Administration, Washington. USA. 80 p.

FAA. 2018. Fact sheet-Engineered Material Arresting Systems. Federal Aviation Administration, Washington. USA.

GCAA. 2016. Air Accident Investigation, report AIFN/0008/2016. General Civil Aviation Authority, Dubai

ICAO. 2006. Aerodrome Design Manual, Part 1 - Runways, Doc 9157 AN/901. Montreal, Canada. 86 p.

ICAO. 2007. Manual on the prevention of runway incursion. International Civil Aviation Organization, First edition, Montreal, Canada. 90 p.

ICAO. 2009. Safety Management Manual (SMM). Doc 9859. International Civil Aviation Organization, Second edition, Montreal. $263 \mathrm{p}$.

ICAO. 2016. Annex 14 Aerodromes, Volume I Aerodrome Design and Operations. International Civil Aviation Organization, Seventh edition, Montreal, Canada. 352 p.

Moretti, L.; Di Mascio, P.; Nichele, S.; Cokorilo, O. 2018. Runway veer-off accidents: quantitative risk assessment and risk reduction measures, Safety Science 104: 157-163.

Safe-Runway. 2018. Available from internet: <https:// www.safe-runway.com/>.

van Eekeren, R.; Wright, S.; Čokorilo, O. 2017. Costbenefit assessment of aircraft safety, International Journal for Traffic and Transport Engineering 7(3): 283-297. 